\title{
Medicinal plants in the prevention and treatment of rheumatoid arthritis
}

\begin{abstract}
Rheumatoid arthritis is a chronic, inflammatory disorder that may affect many tissues and organs, but principally attacks flexible (synovial) joints. The process produces an inflammatory responses of the capsule around the joints, secondary swelling of the synovial cells. The aim in this review is to collate all available data on experiments reporting the anti-arthritic effect of plants and natural products in the last two decades. A bibliographic investigation was carried out by analyzing recognized books and peerreviewed papers, consulting worldwide accepted scientific databases (Scirus, Embase, HighWire, MEDLINE/PubMed, Science Direct, Google Scholar). We used medical subject heading terms and the words "Anti-arthritic", "Bone disease", "Medicinal Plants", to identify relevant articles. In the present study, interest is focused on experimental research conducted on medicinal plants, particularly those which show anti-arthritic activities alongside bioactive components. A total of 11 plant species have been identified as active or promising sources of phytochemicals with antiarthritic properties.
\end{abstract}

Keywords: rheumatoid arthritis, bone disease, anti-arthritic activity, inflammatory, freund's complete adjuvan
Volume 5 Issue I - 2018

\author{
Ghizlane Hajja,' Aziz Bahlouli² \\ 'Department of drugs Sciences, MohammedV University, \\ Morocco \\ 2Laboratory of applied chemistry and quality control, Ibn Tofail \\ University, Morocco
}

\author{
Correspondence: Ghizlane Hajja, Laboratory of Pharmacology \\ and Toxicology, Department of Drugs Sciences, Faculty of \\ Medicine and Pharmacy, MohammedV University, ERTP, BP 6203, \\ Rabat Instituts, Agdal, Rabat, Morocco, \\ Email hajiajghizlanel@gmail.com
}

Received: December 18, 2017 | Published: February 21, 2018
Abbreviations: RA, rheumatoid arthritis; FCA, freund's complete adjuvant; PVM, polygonum viviparum l. methanol; TAPP, type-a procyanidine polyphenols; CPE, carrageenan-induced rat paw edema; AIA, adjuvant induced established arthritis; CRP, c-reactive protein; SGOT, serum glutamate oxalo acetate transferases; SGPT, serum glutamic pyruvic transaminase

\section{Introduction}

The word arthritis means inflammation of the joint ("artho" meaning joint and "itis" meaning inflammation). Rheumatoid arthritis (RA) is a ravaging inflammatory and autoimmune illness that affects the joints. Although its cause is still unknown. With RA, inflammation manifests in the lining of the joints causing pain, swelling, joint damage and deformity. It can occasionally involve other internal organs, such as the nerves, eyes, lungs or heart. The earliest symptoms of RA can be non-specific, including feeling unwell or tired soreness in or around joints, low-grade fever, and weight loss/poor appetite. As time goes on, RA can involve more and more joints on both sides of the body, often in a "symmetrical" pattern. Although various drugs have been used to control RA, there are numerous reports regarding the side effects of these drugs. A range of newer drugs called TNF blockers have been linked to a condition called leukocytoclastic vasculitis, or LCV. TNF blockers, specifically Humira and Remicade, reportedly increase the risk of cancer and serious infections. As a consequence, researchers are now searching for alternatives therapeutics. ${ }^{1-3}$

\section{Effect of medicinal plants on rheumatoid ar- thritis}

Inflammatory and arthritic conditions are among those treated using traditional remedies, with considerable success. Chronic inflammatory diseases including rheumatoid arthritis are still one of the main health problems of the world's population. Although several modern drugs are used to treat these types of disorders, their prolonged use may cause severe adverse side effects on chronic administration, the most common being gastrointestinal bleeding and peptic ulcers. Consequently there is a need to develop new anti-inflammatory agents with minimum side effects. It is worthwhile to note that most of the present day analgesic drugs also exert a wide range of side effects.

Most of the tribal people still depend on local medicinal plants for the treatment of different diseases using the knowledge of herbal treatment they have inherited from their forefathers. But this ethnomedicinal knowledge and also the medicinal plants are depleting at an alarming rate due to availability of modern medical facilities and other socio-economic factors. On the other hand, this knowledge is valuable in searching new medicine for human welfare. In recent years interest in herbal medicines has increased considerably both at home and abroad as they are believed to be comparatively less toxic than the synthetics.

\section{Anti-arthritic activity of Glycyrrhiza glabra, Boswellia serrata}

Glycyrrhiza glabra (liquorice) is a herb belonging to the pea and bean family, liquorice is cultivated for its underground stems that are used to flavour confectionery; it is also valued for its medicinal qualities. In the traditional system of medicine, the roots and rhizomes of Glycyrrhiza glabra (Family: Leguminosae) have been employed clinically for centuries for their anti-inflammatory, antiulcer, expectorant, antimicrobial and anxiolytic activities. In modern medicine, liquorice extract has been used for peptic ulcer and as an alternative to bismuth that has a protective role against acid and pepsin secretions by covering the site of lesion and promoting the mucous secretion. There are many useful compound in liquorice root such as, glycyrrhizin and its aglycone, glycyrrhetinic acid wich are clinically used for hyperlipidemia. Liquorice flavonoid constituents mainly include flavones, flavonals, isoflavones, chalcones, bihydroflavones and bihydrochalcones. A pharmacological investigation indicates that they have antioxidant, antibacterial and anti-inflammatory activities. ${ }^{4,5}$ 
On the other hand Boswellia serrata (Family: Burseraceae; Genus: Boswellia), a large branching tree, grows abundantly in dry hilly parts of India, Northern Africa and the Middle East (Selected Medicinal Plants of India, 1992). The gum resin exudate of Boswellia serrata is known as Salai guggal in the vernacular and is used in ayurvedic system of medicine for the treatment of rheumatism, obesity and various other disorders. ${ }^{6,7}$ Chemically it is reported to contain gum, resin, terpenoids and essential oils. A non-phenolic fraction obtained from its gum resin is reported to possess analgesic and psychopharmacological effects. In India the resin of Boswellia serrata is used for the treatment of chronic inflammatory arthritis. Extracts of Boswellia serrata have been clinically studied for osteoarthritis and joint function, particularly for osteoarthritis of the knee, with the research showing a slight improvement of both pain and function compared to a placebo. Positive effects of Boswellia in some chronic inflammatory diseases including rheumatoid arthritis, bronchial asthma, osteoarthritis, ulcerative colitis and Crohn's disease have been reported.

In a study the investigation was undertaken to assess the antiarthritic activity of Glycyrrhiza glabra and Boswellia serrata. Then Glycyrrhiza glabra and Boswellia serrata extracts were combined to study the synergistic property for potent anti-arthritic activity. The methanolic extract of Glycyrrhiza glabra was administered orally at a dose of $150 \mathrm{mg} / \mathrm{kg}$ and $\mathrm{n}$-hexane extract of Boswellia serrata was administered $50 \mathrm{mg} / \mathrm{kg}$ body weight for 21 days to the experimental animals after the induction of adjuvant arthritis. Further the combined formulation containing both Glycyrrhiza glabra and Boswellia serrata $100 \mathrm{mg} / \mathrm{kg}$ was administered in separate group. Different biochemical estimations were carried out like paw edema volume, lysosomal enzyme activity such as ACP, membrane bound enzymes like SGPT, SGOT and ALP, Total WBC count, different in vitro parameters like Proteinase inhibitory action and inhibition of Protein denaturation for the evaluation of anti- arthritic property. The anti-arthritic activity of Glycyrrhiza glabra and Boswellia serrata were assessed by significant reduction of paw edema volume and its capacity to stabilize lysosomal enzyme activity such as ACP significantly ( $\mathrm{P} \mathrm{d}$ " 0.01). Furthermore the combined formulation containing both Glycyrrhiza glabra and Boswellia serrata at proportion (1:1) showed significant synergistic action. As a better synergistic activity was observed in combined formulation it may be tried for therapeutic use clinically. ${ }^{8}$

\section{Antiarthritic activity of Strychnos potatorum (Linn.)}

Strychnos potatorum (Linn.) belongs to family Loganiaceae, commonly known as Katakam in Ayurvedic system of medicine, is a moderate-sized tree found in southern and central parts of India, Srilanka and Burma. According to Ayurveda, its seeds are acrid, alexipharmic, lithotriptic and cure strangury, urinary discharges and head diseases. In Unani system of medicine, seeds are used in liver and kidney complaints, gonorrhea and for colic. The ripe seeds are used for clearing muddy water.

Biswas et al. ${ }^{9}$ studied on the diuretic and antidiarrhoeal activities of Strychnos potatorum Linn. Seed extract in albino rats and found it quite worthy. Due to polysaccharide gum its seeds are utilized in paper and textile industries. Roots cure leucoderma, whereas fruits are useful in eye diseases, thirst, poisoning and hallucinations. Its seeds are used to purify water for drinking. In traditional system of medicine, Strychnos potatorum (Linn.) seeds were used for various ailments including inflammation, diabetes etc. Although Strychnos potatorum Linn is widely used in traditional medicine, there exists a controversy on its toxic effect as expected with another species Strychnos nuxvomica. ${ }^{10}$

In a study the folkloric use of the seeds was carried out on Freund's adjuvant induced arthritic rats. The methodology of the study states the effect of the aqueous extract (SPE) and the whole seed powder (SPP) of Strychnos potatorum Linn seeds on the Freund's complete adjuvant (FCA) induced arthritic rat paw edema, body weight changes and alterations in haematological and biochemical parameters in both developing and developed phases of arthritis. Histopathology of proximal interphalangeal joints and radiology of hind legs were studied. As a results in FCA induced arthritic rats, there was significant increase in rat paw volume and decrease in body weight increment, whereas SPP and SPE treated groups, showed significant reduction in paw volume and normal gain in body weight. The altered haematological parameters ( $\mathrm{Hb}, \mathrm{RBC}, \mathrm{WBC}$ and $\mathrm{ESR})$ and biochemical parameters (blood urea, serum creatinine, total proteins and acute phase proteins) in the arthritic rats were significantly brought back to near normal by the SPP and SPE treatment at the dose of $200 \mathrm{mg} / \mathrm{kg} / \mathrm{p} . \mathrm{o}$ in both developing and developed phases of arthritis. Further the histopathological and radiological studies revealed the antiarthritic activity of SPP and SPE by indicating fewer abnormalities in these groups when compared to the arthritic control group. As a conclusion, both SPP and SPE at the specified dose level of $200 \mathrm{mg} / \mathrm{kg} /$ p.o. showed reduction in rat paw edema volume and it could significantly normalize the haematological and biochemical abnormalities in adjuvant induced arthritic rats in both developing and developed phases of FCA induced arthritis. Further the histopathological and radiological studies confirmed the antiarthritic activity of SPP and SPE. ${ }^{11}$

\section{Anti-arthritic activity of Urtica pilulifera $L$.}

Urtica pilulifera L. Stinging nettle (Urticaceae) are annual and perennial herbs, distinguished with stinging hairs. Leaves are opposite. Flowers are green with yellow stamens, the male and female flowers on separate plants. Fruits are achene. These are the characters of Urtica genus which belong to the family Urticaceae. The main varieties identified under the Urtica species are Urticadioica $L ., U$. urens L., Urtica pilulifera L., U. cannabina L., U. membranacea Poiret, U. kiovensis Rogoff. Among these, U. dioica and U. urens have already been known for a long time as medicinal plants in the world. They are used as an expectorant, purgative, diuretic, hemostatic, vermifuge and for the treatment of eczema, to alleviate inflammation, rheumatism, haemorrhoids, hyperthyroidism, bronchitis and cancer. Keeping in mind that these plants are being consumed without any report of adverse effect. For instance, $U$. dioica is amongst several species listed for their use against diabetes in folk medicine. In a large pharmacological screen of European species with known potential anti-diabetic effects, Max-Neef et al. ${ }^{12}$ have detected hyperglycemic activity of $U$. dioica. A less known Urticaceae member $U$. pilulifera $L$. Roman nettle locally, named 'Kara Isirgan', is one of the most important traditional drugs in Turkey. All parts of the plant bristle with stinging hairs and it flowers from May to August. In Turkish traditional folk medicine this plant is commonly used as a remedy for diabetes mellitus. Up to this day such use of $U$. pilulifera $L$. is quite prominent in the Black Sea region of Turkey. Despite several experimental studies on other Urtica species, there is currently no pharmacological literature on U. pilulifera $L .^{13}$

In a study the anti-arthritic effect of methanolic leaf extract of the plant was evaluated and compared to untreated control as well 
as ibuprofen-treated groups in a rat model of Complete Freund's Adjuvant (CFA)-induced arthritis. The arthritis was induced by injecting CFA subcutaneously into the right paw. The extract was given orally one day before CFA injection up to the completion of study (for 30 days). Two extract doses ( 1.33 and $\left.2.0 \mathrm{~g} \mathrm{~kg}^{-1}\right)$ and ibuprofen $(53 \mathrm{mg}$ $\mathrm{kg}^{-1}$ ) as a positive control were used. Paw volume was measured on alternate days up to 30 days. In addition, the effect of the extract on joint deformity, ankle swelling and inflammatory markers was evaluated. As results the extract prevented arthritis-induced increase in paw volume and joint deformity dose-dependently as compared to control. Moreover, the extract showed significant increase in the packed cell volume $[\mathrm{p}<0.05]$. No alteration of kidney or liver function tests was detected in rats during repeated dose treatment. This study supports the traditional use of Urtica pilulifera for the treatment of inflammatory disorders and rheumatoid arthritis and suggests further evaluation for its role in increasing red blood cells. ${ }^{14}$

\section{Anti-arthritic activity of Polygonum viviparum $L$.}

Polygonum viviparum Linn. (Family: Polygonaceae), P. viviparum is widely distributed in both arctic and alpine regions of the northern hemisphere between 1,900 and $4,200 \mathrm{~m}$ above sea level, and is representative of a common growth habit (herbaceous perennial) within these environments. As P. viviparum is very common and important species of tundra plant communities, it has been the subject of numerous ecological studies. Recent studies also proved that $P$. viviparum is the ectomycorrhizal host in alpine. Although adaptive strategies expressed in $P$. viviparum have been made by on physiological parameters and processes, by Lutz and Engel (2007) on chloroplast ultrastructure and by on the formation of chloroplast protrusions, not enough is known about the physiological, biochemical, and molecular mechanisms which protect $P$. viviparum against unfavorable environmental stresses. In folk medicine it is used for the following: treatment of wounds, diarrhoea, fever from pneumonia, and large and small intestine diseases. It also relieves cough and promotes expectoration. The taste of $P$. viviparum is sour and the potency is easy and cool. It is an ingredient of the following traditional prescriptions: Bragshun-9, Gunbrum-7, Dali-16, Donshin-4, Zobo-25, Lotsadgunsel, Martan-11, Srol-4, Tiche-7, Jugan-25, and Indra- $4 .{ }^{15}$

In a study the effects of polygonum viviparum $L$. methanol extract (PVM) of rhizome was on vestigated on acute and chronic inflammation. As methods the acute inflammation carrageenan and dextran induced paw edema assays were used whereas chronic inflammation was assessed by mycobacterium induced arthritis and formaldehyde arthritis. Mechanism of action was predicted on the basis of the following assay models viz., carrageenan edema in adrenalectomized rat, castor oil-induced diarrhoea, pleurisy in rats, effect on gestation period and ulcerogenic effect.

As results this study revealed a significant reduction of paw inflammation both in acute and chronic inflammatory models up to 250 $\mathrm{mg} / \mathrm{kg}$. In acute inflammation the inhibition was 18 to $34 \%$ whereas the reduction of the chronic inflammation was ranging up to $44 \%$. It also inhibited the elevated levels of biochemical and hematological parameters such as SGPT, ESR and TLC in arthritic animals. Nontheless, PVM also showed significant inhibition of the exudate volume and total count of pleural fluid. It did not show any analgesic, antipyretic, antidiarrhoeal and ulcerogenic activity. In conclusion PVM showed significant anti-inflammatory and anti-arthritic activity, without any analgesic, antipyretic and ulcerogenic activity, devoid of adverse effects of NSAIDs. The inhibitory mechanism seems to be non traditional and also not by one mechanism. ${ }^{16}$

\section{Anti-arthritic activity of Cinnamomum zeylanicum $L$.}

The Lauraceae are an economically important family consisting mostly of trees or tree-like shrubs. The genus Cinnamomum comprises about 250 species, which are distributed in Asia and Australia. The trees grow in South India at altitudes of up to $500 \mathrm{~m}$, but are found mostly below $200 \mathrm{~m}$. The trees flower in January, and fruits ripen during May-August (The Wealth of India, 1992). Cinnamomum zeylanicum (C. zeylanicum), the source of cinnamon bark, leaf and their essential oils, is an indigenous tree of Sri Lanka. Cinnamon bark oil is rich in cinnamaldehyde. Apart from these, b-caryophyllene, linalool and other terpenes are present. Barks of Cinnamomum plants are used as spice and herbal medicine, and Cinnamomum zeylanicum bark contains dimeric, trimeric, and higher oligomeric proanthocyandins with doubly linked bis-flavan-3-ol units in the molecule. This class of proanthocyanidins is known to occur widely in common foods as well as the singly linked proanthocyanidins. In contrast to barks, cinnamon fruits have not been studied well, and little is known about their nonvolatile components because they are untouched natural resources.

Many species of cinnamon yield a volatile oil on distillation. The most important cinnamon oils in world trade are those from $C$. zeylanicum, C. cassia and C. camphora. The other species provide oils which are utilized as sources for chemical isolates. Cinnamon leaf and bark are used as spices and in the production of essential oils. The leaves have a hot taste and emit a spicy odour when crushed. Cinnamon provides a variety of oils with different aroma characteristics and composition to the flavour industry. The root bark was reported to have camphor as the main constituents, but does not seem to have commercial value, unlike the leaf and stem bark oils. ${ }^{17}$ Cinnamon leaf oil has a fragrant odour and a very pungent taste, lacking the rich body of the bark oil. We have reported the volatile oil constituents from the fruits and flowers of cinnamon. ${ }^{18}$ In a study the potential of TAPP extracted from Cinnamon (Cinnamomum zeylanicum) bark in animal models of inflammation and rheumatoid arthritis in rats was evaluated. Type-A procyanidine polyphenols (TAPP) are reported to have immunomodulatory and anti-inflammatory potential in vitro. Carrageenan-induced rat paw edema (CPE) and adjuvant induced established arthritis (AIA), in rats were used as the experimental models for inflammation and arthritis respectively. Analgesic activity was evaluated in Randall-Selitto assay in AIA rats. TAPP showed significant anti-inflammatory effect at dose of 4,8 and $25 \mathrm{mg} / \mathrm{kg}$, p.o. but not at $2 \mathrm{mg} / \mathrm{kg}$, p.o. dose in CPE model. The dose of $8 \mathrm{mg} / \mathrm{kg}$, p.o. was selected for the evaluation of anti-arthritic activity in AIA model. TAPP $(8 \mathrm{mg} / \mathrm{kg}$, p.o., daily from day-12 today-21) treatment in established arthritic rats showed significant reversal of changes induced in AIA with respect to body weight drop (cachexia), ankle diameter, arthritic score, serum C-reactive protein (CRP) levels. Moreover, TAPP was found to be non-ulcerogenic as compared to AIA control rats. However, TAPP did not show analgesic effect on AIA-induced pain as seen in Randall-Selitto assay. As a conclusion, TAPP showed disease-modifying potential in animal models of inflammation and arthritis in rats. ${ }^{19}$

\section{Anti-arthritic activity of Rhaphidophora glauca, Phrynium imbricatum, Steudneracolocasiifolia}

a. Rhaphidophora glauca (Wall.) Schott (Family: Araceae), an 
aroid liane native to the subtropical and warm temperate regions of the eastern Himalaya, are discussed; illustrations and a description of the species are provided together with a brief overview of Rhaphidophora in the eastern Himalaya.

b. Phrynium imbricatum (Family: Marantaceae) is a rigid herb. Leaves large, oblong, Spikes oblong, bracts oblong with obtuse, minutely toothed tips. Fruits usually $3-$ seeded. A paste prepared from leaves of Phrynium imbricatum, Blumea clarkei and an unidentified species (locally called Khedom gas) is applied to affected areas and bandaged for the treatment of fractures (Chakma). Occurs in the forests of Chittagong, Chittagong Hill Tracts, Cox's Bazar and Sylhet.

c. Steudneracolocasiifolia (Family: Araceae) is an evergreen herb, which is short Stem, creeping and ascending; persistent cataphylls brown, not netted. Petiole green, cylindric, $30-50 \mathrm{~cm}$, slender, base sheathing; leaf blade paler but not glaucous abaxially, green adaxially. It is habitat in dense forests, wet meadows, by streams. Seasonally moist lowland forest. Distributed in Bangladesh, India, Myanmar, Thailand and China. Locally it is used to treat injuries, cuts, snake and insect bites and skin ulcers.

In a study three Bangladeshi medicinal plants Rhaphidophora glauca, Phrynium imbricatum, Steudneracolocasiifolia, have been investigated for their in vitro Arthritic and membrane stabilizing activity.

Inhibition proteinase actions were evaluated to assess the antiarthritic effect of the selected plant extracts and membrane stabilizing activity were assessed by using hypotonic solution and heat-induced method. In highest concentration of Rhaphidophora glauca, Phrynium imbricatum, Steudneracolocasiifolia, shows significant antiarthritic activity $(53.16 \%, 69.62 \%, 62.03 \%)$ and membrane stabilizing activity $(49.05 \%, 71.9 \%, 60.22 \%)$ compared with Diclofenac-Na. Further in depth studies on this plant can result in an eco-friendly cost effective antiarthritic herbal drug with antiinflammatory potential contributing towards the better healthcare of human society. ${ }^{20}$

\section{Anti-arthritic potential of Justicia gendarussa burm. $F$.}

Justicia gendarussa is a rare, shade-loving, quick-growing, evergreen scented shrub of the family Acanthaceae, which is considered to be a native of China and distributed in the forests of Sri Lanka, India and Malaysia. $J$. gendarussa is an erect, branched and smooth under shrub with long leaves having acute tips and small flowers on long terminal pinkish spikes with purple spots. The plant is hardy, withstands heavy rainfall and thrives in shade. The plant is known for its medicinal properties in the Indian traditional system of medicine. In traditional medicine, the leaves of the plant are recommended to treat a number of ailments such as fever, hemiplegia, rheumatism, arthritis, muscle pain, lumbago, headache and earache. ${ }^{23}$ The roots and leaves are acrid, bitter, thermogenic, emmenagogic and antiperiodic. Traditionally, a decoction prepared by boiling $J$. gendarussa roots in milk is used for the treatment of chronic rheumatic disorders, dysuria, fever, carbuncles, and diarrhea. The leaves of $J$. gendarussa possess reverse transcriptase inhibitor, analgesic and antioxidant potential. Justicia has been found to contain lignans, naturally occurring phenolic dimers and triterpenoids. Lignans have been used as a lead compounds for the development of antirheumatic agents. ${ }^{21}$

In a study the anti-arthritic potential of the alcoholic extract of the plant Justicia gendarussa was evaluated using the Freund's adjuvantinduced and collagen-induced arthritic rat models. The rats were treated with the ethanolic extract of Justicia gendarussa and with standard aspirin. As results the ethanolic extract of Justicia gendarussa showed significant anti-arthritic activity that was statistically similar to that of aspirin. The results suggest that the alcoholic extract of Justicia gendarussa exhibits significant anti-arthritic potential. ${ }^{22}$

\section{Anti arthritic activity of Hibiscus platinifolius Linn}

Hibiscus platanifolius Linn, is a species of flowering tree in the mallow family, Malvaceae, that is native to the India and Sri Lanka. In Sri Lankan texts, the plant is widely known by its synonym $H$. eriocarpus. The tree is about $8 \mathrm{~m}$ tall. Leaves are cordate at base; hairy; trilobed. Flowers show axillary panicles where flowers show typical Hibiscus flower colors, pink with dark center. Fruit is a capsule. This is well known in Asia and Africa and is commonly used more widely as a natural source of food coloring and used to make wigs. The bark of Hibiscus contains strong baste fibers, these fibers used for making grass skirts. In ayurvedic literature of India, different parts of this plant have been recommended as remedy for various ailments like hyperlipidemic, diabetes, hypertension, liver disorders and as antidotes to poisoning chemicals. Hibiscus petal is used to stimulate thicker hair growth and to prevent premature graying, hair loss and scalp disorders. It acts as a natural emollient hair conditioner and can be used in hair washes and vinegar rinses. A number of active principles from this plant have been identified which include taraxeryl acetate, beta sitosterol, campestral, stigma sterol, cholesterol, erogosterol, lipids, citric, tartaric and oxalic acids, fructose, glucose, sucrose, flavonoids and flavonoid glycosides. However there is no exclusive report on the medicinal values of the leaves of Hibiscus platanifolius Linn. ${ }^{23}$

In a study the anti-arthritic activity of leaves of Hibiscus platinifoliuslinn have been investigated on male Wister rats and estimation of paw edema, body weight measurement and measurement of activity of marker enzymes like alanine trans aminases (SGPT) and serum glutamate oxalo acetate transferases (SGOT) in serum by using Aqueous extract of Hibiscus platinifolius line. The study of anti-arthritic activity involves induction of arthritis to rats of all groups using FCA and turpentine oil induced in i.p route, followed by subsequent treatment with aqueous extraction at two different doses. i.e AEHP $200 \mathrm{mg} / \mathrm{kg}$ and AEHP $400 \mathrm{mg} / \mathrm{kg}$ respectively. Diclofenac sodium is used as a reference standard. paw edemas, paw height, paw volume were estimated from the serum by using Freund's complete adjuvant (FCA) and turpentine oil induced arthritis . The bio chemical parameters were increased in all arthritic rats, there parameters were decreased by the administration of aqueous extraction of Hibiscus platinifolius Linn at dose of $200 \mathrm{mg}$ and $400 \mathrm{mg}$ respectively. From this study it has been concluded that the aqueous extract of leaves of Hibiscus platinifonlius Linn having good anti-arthritic activity, which is comparable to Diclofenac sodium. ${ }^{24-28}$

\section{Conclusion}

Herbal medicines are popular as remedies for diseases by vast majority of world's population. Medicinal plants are a source of great economic value all over the world. Nature has bestowed on us a very rich botanical wealth and a large number of diverse types of plants grow in different parts of the country. There is considerable evidence that plant extracts have the potential to be developed into agents that can be used as preventative or treatment therapies for oral diseases. In 
this review, we have selected some medicinal plants in recent years that highlight some of the main advances achieved in the identification of plants with anti-arthritic activity.

\section{Acknowledgments}

The author Hajjaj ghizlane is thankful to $\operatorname{Pr}$ Tajanimouna. Special thanks to all colleagues and professors at the Laboratory of Pharmacology and Toxicology, Faculty of Medicine and Pharmacy, Mohammed V University, Rabat, Morocco.

\section{Conflicts of interest}

The author declares no conflict of interest.

\section{References}

1. Kavanaugh A, Cohen S, Cush JJ. The evolving use of tumor necrosis factor inhibitors in rheumatoid arthritis. J Rheumatol. 2004;31(10):18811884 .

2. Mohan N, Edwards ET, Cupps TR, et al. Leukocytoclastic vasculitis associated with tumor necrosis factor-alpha blocking agents. J Rheumatol. 2004;31(10):1955-1958.

3. Dharamsiri M, Jayakody J, Galhena G, et al. Anti inflammatory and analgesic activities of mature fresh leaves of Vitex negundo. $J$ Ethnopharmacol. 2003;87(2-3):199-206.

4. Fiore C, Eisenhut M, Ragazzi E, et al. A history of the therapeutic use of liquorice in Europe. J Ethnopharmacol. 2005;99(3):317-324.

5. Olukoga A, Donaldson D. Liquorice and its health implications. $J R$ Soc Promot Health. 2000;120(2):83-89.

6. Kirtikar KR, Basu BD. Indian Medicinal Plants. (Plates Vol. I). Panin Office, Bhuwaneshwari Ashram, India; 1918.

7. Chatterjee G, Pal S. Anti-inflammatory agents from Indian medicina plants. Indian Drugs. 1984;21:431.

8. Mishra NK, Bstia S, Mishra G, et al. Anti-arthritic activity of Glycyrrhiza glabra, Boswellia serrata and their synergistic activity in combined formulation studied in freund's adjuvant induced arthritic rats. $J$ Pharm Educ Res. 2011;2(2):92-98.

9. Biswas K, Chattopadhyay I, Baerjee RK, et al. Biological activities and medicinal properties of neem (Azadirachtaindica). Curr Sci. 2002;82(11):1336-1345.

10. Srikanth k, vikram G, Madhusudhan k, et al. Recent advances in elucidating the biological and chemical properties of Strychnos potatorumlinn. F. - a review. Int J Pharm Bio Sci. 2012;3(4):291-303.

11. Sanmugapriya E, Senthamil SP, Venkatarama S. Evaluation of antiarthritic activity of Strychnos potatorum Linn seeds in Freund's adjuvant induced arthritic rat model. BMC Complement Altern Med. 2012;10:56.

12. Max-Neef M. Economic growth and quality of life: a threshold hypothesis. Ecological Economics. 1995;15(2):115-118.
13. Gulsel M Kavalali. Urtica: therapeutic and nutritional aspects of stinging nettles. New York: Taylor \& Francis; 2003. 83 p.

14. Suha A, Ahmad D, Eyad Q, et al. Anti-Arthritic Activity of the Methanolic Leaf Extract of Urtica pilulifera L. on Albino Rats. American Journal of Pharmacology and Toxicology. 2011;6(1):27-32.

15. Diggle PK, Meixner MA, Carroll AB, et al. Barriers to Sexual Reproduction in Polygonum viviparum: A Comparative Developmental Analysis of P. viviparum and P. bistortoides. Ann Bot. 2002;89(2):145156.

16. Surjeet S, Rohit S, Gurdarshan S, et al. Anti-inflammatory and anti-arthritic activity of the rhizome extract of Polygonum viviparum L. Spatula DD. 2011;1(4):225-232.

17. Senanayake UM, Lee TH, Wills RBH. Volatile constituents of cinnamon oils. J Agric Food Chem. 1978;26(4):822-824.

18. Jayaprakasha GK, Jaganmohan, Rao L, et al. Chemical composition of the flower oils of Cinnamomum zeylanicum blume. J Agric Food Chem. 2000;48(9):4294-4295.

19. Sachin V, Subhash LB, Vishwaraman M, et al. Anti-inflammatory and anti-arthritic activity of type-A procyanidine polyphenols from bark of Cinnamomum zeylanicum in rats. Food Science and Human Wellness. 2013;2(2):59-67.

20. Mohammed MH, Mohammad SHK, Abul Hasanat, et al. Investigation of in vitro anti-arthritic and membrane stabilizing activity of ethanol extracts of three Bangladeshi plants. The Pharma Innovation Journal. 2015;4(1):76-80.

21. Ahmad F, Holdsworth D. Medicinal plants of Sabah, East MalaysiaPart I. Pharm Biol. 2003;41(5):340-346.

22. Sastri BN. Wealth of India: Raw materials. V. Council of Scientific and Industrial Research, New Delhi, India; 1959. p. 312-313.

23. Paval J, Kaitheri SK, Potu BK, et al. Anti-arthritic potential of the plant Justicia gendarussa Burm F. Clinics (Sao Paulo). 2009;64(4):357-362.

24. Saravanan D, Aparna lakshmi I, Gobinath M, et al. Potential Antioxidant, Hypoglycemic and Hypolipidemic Effect of Leaves of Hibiscus platanifolius Linn. IJPSDR. 2011;3(3):236-240.

25. Marri P, Janarthan M. Evaluation of anti arthritic activity of aqueous extract of Hibiscus platinifolius in albino rats. IJRPB. 2013;815-818.

26. Jayasinghe D. Ayurveda Pharmacopeia. Department Ayurveda, Colombo, Sri Lanka; 1979. p. 30-32.

27. Sastri MVC, Viswanathan TS, Nagarjunan TS. The Influence of a Chemisorbed Layer of Carbon Monoxide on Subsequent Physical Adsorption. J phys Chem. 1959;63(4):518-521.

28. Swami PN. Selected Medicinal Plants of India (A monograph of identity, safety, and clinical usage) Compiled by Swami Prakash nanda. Ayurved Research Centre (SPARC) for Chemixil. India: Tata Press; 1992. p. 65-66. 